\title{
Effects of Playfulness of Early Childhood Teachers on Their Interaction with Young Children: Mediating Effects of Positive Play Beliefs
}

\author{
Su Mi Lim ${ }^{1}$, Hae Shin Hwang ${ }^{2}$ \\ Ph. D. Student, Department of Family Welfare, Sangmyung University, Seoul, Korea ${ }^{1}$ \\ Professor, Department of Family Welfare, Sangmyung University, Seoul, Korea ${ }^{2}$ \\ 유아교사의 놀이성이 교사-유아의 상호작용에 미치는 영향: \\ 긍정적 놀이신념의 매개효과 \\ 임수미 ${ }^{1}$, 황혜신 ${ }^{2}$ \\ 상명대학교 가족복지학과 석 · 박사 과정 ${ }^{1}$ 상명대학교 가족복지학과 교수 ${ }^{2}$
}

Objectives: This study aimed to examine the effects of playfulness of early childhood teachers on their interaction with children in the early childhood stage, and to verify the mediating effects of teachers' positive play beliefs on the relationship between them.

Methods: Using the questionnaire survey method targeting 269 early childhood teachers, this study aimed to measure the playfulness and positive play beliefs of early childhood teachers, and examine their effects on the interaction between the teacher and young children. The mediating effects were analyzed by applying the structural equation model using SPSS 21.0 and SPSS Amos 21.0, as well as the bootstrapping method.

Results: With the mediation of positive play beliefs, playfulness of early childhood teachers was shown to have significant indirect effects on the emotional, linguistic, and behavioral interaction between teacher and young children.

Conclusion: The playfulness of early childhood teachers not only has direct effects on the interaction between teacher and children in the early childhood stage, but also has indirect effects on it with the mediation of positive play belief. It is therefore important for early childhood teachers to possess positive play beliefs by internalizing the value and importance of play based on their own playfulness.

Keywords: playfulness, positive play beliefs, early childhood teachers

\section{Introduction}

어린이집에서 유아는 하루 중 긴 시간을 교사와 함께 경험하 고 활동하며 삶에 필요한 지식과 기능을 습득해 나간다. 유아 는 교사를 통해서 자신의 정서와 생각을 자신이 포함된 사회 와 문화에 맞는 방식으로 표현할 수 있도록 행동기준을 배우

Corresponding Author: Hae Shin Hwang, Professor, Department of Family Welfare, Sangmyung University, 20, Hongjimun 2-gil, Jongno-gu, Seoul, Korea

E-mail: hshwang@smu.ac.kr
고 실천하는 데 도움을 받는다. 유아교사의 역할은 시대적인 변화나 문화, 정책 등에 따라 달리 규정되어 그 역할을 한 마 디로 말하기는 어렵지만 유아교사가 수행하는 여러 역할 중 에서 상호작용자로서의 역할은 매우 중요한 것으로 간주된 다. 왜냐하면 어린이집에서 교사-유아의 경험과 활동은 많 은 부분이 교사와 유아의 상호작용을 통하여 이루어지고(de

(C)The Korean Association of Child Studies

This is an Open Access article distributed under the terms of the Creative Commons Attribution Non-Commercial License (http:// creativecommons.org/licenses/by-nc/4.0) which permits unrestricted noncommercial use, distribution, and reproduction in any medium, provided the original work is properly cited. 
Kruif, McWilliam, Ridley, \& Wakely, 2000; Downer, Sabol, \& Hamre, 2010), 교사와 유아의 상호작용의 질은 유아의 발달 에 직접적으로 영향을 미치기 때문이다(Dickinson, Darrow, \& Tinubu, 2008; Vandell, 2004).

교사-유아 상호작용의 중요성은 교사-유아의 상호작용 이 유아의 성장과 발달에 미치는 긍정적인 영향을 분석한 연 구 결과들에 의해 확인된다(H. J. Cho \& Kim, 2007; TrawickSmith \& Dziurgot, 2011). 예를 들어, 교사와 유아의 긍정적인 상호작용은 유아에게 자신감과 성취하고자 하는 동기를 주 고, 환경적인 요구를 적절하게 판단하고 처리하도록 지원해 주며 또래 간의 사회적 활동에 긍정적으로 영향을 미치는 것 으로 나타났다(Dan, 2011; M. J. Kim, 2013). 교사와 유아의 민감하고 반응적인 상호작용은 긍정적으로 유아의 탐색능력 을 발달시키고(M. S. Choi \& Hwang, 2007) 유아의 과제 집중 력을 높여(Wee \& Park, 2007), 수준 높은 인지적 발달을 돕는 것으로 알려졌다(S.-K. Lee \& Kim, 2016). 또한 교사와 유아의 관계가 안정적일수록 유아의 긍정적인 자아개념 발달에 도 움을 주고(Leflot, Onghena, \& Colpin, 2010) 유아의 적대적 공 격성을 낮추는 것으로도(H. J. Shin \& Shin, 2014) 보고되었다. 이처럼 교사-유아의 상호작용은 유아의 전반적인 발달영역 에 영향을 미침으로써 보육의 질을 가늠하는 핵심 요인임을 확인할 수 있다.

교사-유아 상호작용의 중요성은 등원에서 귀가까지 대부 분이 교사-유아 상호작용에 의해 이루어지는 어린이집에서 보편적 가치로 자리 잡고 있으며, 교사-유아의 상호작용이 곧 보육의 질(Downer et al., 2010)이라고 인식되고 있다. 즉, 교 사-유아의 상호작용은 어린이집에서 교사가 유아와 함께 하 는 정서적, 언어적 및 행동적 상호작용으로 교사는 유아의 일 상적 양육과 상호작용을 통해 유아의 개별적 차이를 이해하 게 되며, 유아에게 발달적으로 적합한 경험을 제공할 수 있게 된다.

교사-유아 상호작용의 중요성에 대한 인식을 바탕으로 교 사-유아의 상호작용을 지원할 수 있는 방법에 대한 연구가 활 발히 이루어지고 있는데, 많은 연구에서 교사-유아 상호작용 의 내용과 질을 결정하는 주요 변수로 교사의 교육수준이나 훈련기간(Chung, Lee, \& Kang, 2016; H.-C. Kim, 2008), 교사 효능감(Han \& Huh, 2016; Moon, 2005) 또는 직무만족도(B. K. Cho, Go, \& Park, 2003; J.-S. Choi \& Kim, 2014)를 제안하 고 있다. 즉, 교육수준이 높고, 유아의 성장과 발달에 대한 지 식이 많으며, 훈련을 더 많이 받은 교사가 유아와의 상호작용 에 더욱 긍정적이고, 유아교사의 교사 효능감 또는 직무만족
도가 교사-유아의 상호작용을 높인다는 것이다. 이러한 연구 들은 교사의 전문성과 직무요인에 초점을 두고 연구가 이루 어졌음을 보여주는 것으로 교사행동 이면에 있는 유아교사 의 성향, 가치, 신념과 교사-유아 상호작용의 관련성에 대한 탐색이 필요함을 확인할 수 있다.

교사-유아 상호작용의 중요성에 대한 보편적 인식과는 다 르게 교사-유아의 상호작용을 탐색하는 연구에서는 어린이 집의 하루일과 전체를 교사-유아 상호작용의 관점에서 살피 기보다는 하루일과 중 유아의 놀이와 수업을 중심으로 유아 교사의 상호작용을 탐색한 연구가 대부분이다. 즉, 하루일과 를 교사가 주도하는 집단 활동과 유아의 놀이가 이루어지는 자유선택활동으로 구분하여(Shim et al., 2014), 자유선택활 동시간을 중심으로 놀이와 수업에서의 교사-유아의 상호작 용을 지원할 수 있는 조건과 교사-유아의 상호작용을 탐색하 는 연구가 많은 것이다(S. Kim \& Kim, 2006; B.-Y. Lim, Oh, \& Choi, 2008). 이는 교사와 유아의 놀이 상호작용의 가치와 중 요성에서 비롯된 것으로 유아의 놀이가 보육과정이나 학습 과 분리되어 일어나는 것이 아닌 어린이집에서의 하루일과 전체에서 서로 자연스럽게 그 범위를 넘나들며 연계되어 이 루어진다는 점을 감안하여 살펴볼 필요가 있다고 할 수 있다.

보육의 질을 가늠할 수 있는 결정적인 요인이 교사-유아 상호작용의 질임을 인식하고 교사-유아 상호작용의 중요성 을 지향한다면, 어린이집의 하루일과 전체를 교사-유아 상호 작용의 관점에서 살피면서, 교사-유아의 상호작용을 지원할 수 있는 방법을 모색하는 노력이 필요하다.

이 연구는 이러한 문제의식에서 우선 유아교사 개인의 내 적변인 중에 하나인 놀이성과 교사-유아 상호작용과의 관련 성을 살펴보고자 한다. 놀이성은 어떤 환경도 즐겁고 재미있 는 놀이 같은 것으로 만들 수 있는 개인의 내적동기 및 성향 으로서 성격 특성 중 하나이다. 교사-유아의 상호작용에 영 향을 미치는 선행변인으로 유아교사의 놀이성에 중점을 두 고자 하는 것은 놀이성은 즐거움, 관심, 참여를 높이는 행동 으로 설명될 수 있으며(Glynn \& Webster, 1992; Park \& Kim, 2004), 자발적 동기 및 창의력과 같은 놀이의 근본적 특성 $(\mathrm{H}$. Lee, Jo, \& Lee, 2010)과 관련이 있기 때문이다. 놀이성이 높은 사람은 주어진 자신의 상황을 더 적극적이고 즐겁게 만들고, 일이나 관계 맺기 등의 수행능력에 있어서도 뛰어난 것으로 밝히고 있다(Barnett, 2007; Schaefer \& Greenberg, 1997). 즉, 유아교사가 어린이집의 하루일과 전체에서 유아와의 놀이뿐 아니라 일상생활에서도 즐거워서 유아와 함께하고자 하는 내적동기가 있다면, 상호작용자로서의 역할을 더 잘 수행할 
것으로 예측할 수 있다.

그러나 유아들이 하루 중 긴 시간을 머물며 다양한 놀이와 일상생활을 하는 어린이집의 유아교사를 대상으로 하는 놀 이성 연구는 미흡하며, 놀이뿐 아니라 일상생활을 포함한 어 린이집의 하루일과 전체의 관점에서 교사의 놀이성이 발휘 될 수 있음을 고려한 연구는 거의 이루어지지 않았다. 교사의 놀이성이 유아의 문제행동지도전략(Kwon, 2013)이나 음률지 도의 적극성(I. Lee \& Lee, 2016; H. Lim \& Bang, 2017)에 긍정 적으로 작용한다는 선행연구를 근거로 할 때, 유아교사의 놀 이성은 교수행동에 영향을 미칠 것으로 예상할 수 있다. 대부 분 유아들의 일상생활 및 놀이경험이 주로 어린이집에서 하 루 중 많은 시간 생활하며 이루어진다는 것을 감안하면 어린 이집에서 유아의 놀이를 포함한 일상생활을 관찰하고, 지지 하며 개입하는 등 유아의 하루일과의 질에 중요한 영향을 미 치는 유아교사의 놀이성이 교사-유아 상호작용에 영향을 미 치는 내적 변인인지 탐색해 볼 필요가 있다.

한편 이 연구에서는 유아교사의 놀이성과 함께 교사-유아 의 상호작용에 영향을 미칠 것으로 예측되는 변인으로 유아 교사의 긍정적 놀이신념을 살펴보고자 한다. 유아교사의 긍 정적 놀이신념은 놀이가 유아의 발달을 촉진하고 유아가 놀 이를 통해 전인적 발달을 이룰 수 있다는 믿음으로 유아의 놀 이에 접근하는 유아교사의 행동에 영향을 미치는 것이다(E. Shin, 2000). 특히 유아교사는 유아 놀이의 관찰, 놀이 환경의 조성, 놀이에 참여하는 과정에서 유아교사의 긍정적 놀이신 념에 의해 행동을 결정하게 되므로 놀이에 대한 교사의 행동 은 유아의 놀이에 중요한 요인으로 알려져 있다(E. Shin, Yu, $\&$ Park, 2004). 즉, 유아교사가 유아의 놀이에 대해 어떠한 인 식을 가지고 있는가에 따라 유아가 즐겁게 놀이를 할 수 있도 록 환경을 마련하며 유아와의 놀이에 적극 참여하여 유아와 상호작용을 하는 등 교사의 역할을 수행 할 수 있다는 것이 다. 놀이성이 높은 사람은 어려운 상황을 새로운 도전으로 여 기고, 배울 수 있는 기회, 자신을 성장 시킬 수 있는 기회로 인 식하여 문제 상황에 맞는 창의적인 해결방법을 찾아내려는 성향이 있는데(Guitard, Ferland, \& Dutil, 2005) 이러한 성향 은 즐거움과 재미를 바탕에 두고 자발적 동기라는 놀이의 속 성과 그 뜻을 같이하므로 놀이성이 높은 유아교사가 놀이의 가치와 중요성에 대해 보다 긍정적인 놀이신념을 내면화 할 수 있을 것으로 예측된다.

Froebel (1887)은 놀이가 유아의 내적 세계에 무엇이 담겨 있는지 자유롭게 표현하는 가장 만족스러운 행동 양식이고, 유아기의 발달적 본능을 바르게 길러주는 최고의 방법이라
고 정의하였다. 그만큼 놀이는 유아의 발달과 밀접한 관련이 있으며 놀이는 유아의 발달을 지지하고 도와주는 것이라고 할 수 있다. 유아는 놀이를 통해 긍정적 정서를 갖게 되고, 놀 이를 즐기는 것뿐만 아니라 유아의 환경, 타인, 자신과 상호 작용 하면서 새로운 지식과 기술을 형성하고 확장할 수 있도 록 하는(de Kruif et al., 2000) 학습 과정으로서의 가치도 내포 하고 있다. 이처럼 놀이가 유아의 전인적 발달과 밀접한 관련 이 있고, 유아의 학습과 발달에 있어서 목적과 수단의 기능을 수행하기 때문에 교사의 놀이신념은 유아의 발달과 학습에 대한 교사의 일반적 신념에 기초가 된다고 예상할 수 있다.

신념은 주어진 상황에서의 주장이나 의견, 판단 등을 의미 있게 받아들여 개인의 행동에 지속적으로 영향을 주는 것으 로(Sigel, 1992), 교사의 일반적 신념은 예비교사교육의 교육 과정과 현직교사 경험, 교사연수 및 전문서적 등을 통해 교수 활동 경험을 교사 자신의 일반적 신념으로 해석하고, 교수 실 제를 적극적으로 구성하는 과정으로 이루어진다(Robinson \& Schwartz, 1982; E. Shin et al., 2004; Spodek, 1985). Spodek과 Rucinski (1984)는 교실에서 의사결정의 기초가 되는 교사들 의 일반적 신념을 분석한 결과, 유아교사는 유아의 성장과 발 달을 이끄는 방법 중 주로 놀이 활동과 관련된 신념이 많았다 고 밝히고 있다. 유아교사의 일반적 신념은 보육과정은 어떠 해야 하는지, 보육과정 속에서 유아에게 놀이는 어떠한 영향 을 주는지, 유아의 놀이에 교사의 참여가 어떠한 영향을 주는 지에 관한 것으로, 이러한 유아교사의 일반적 신념은 교수행 동의 계획과 실행에 중요한 영향을 미치게 되는 것이다.

유아교사의 긍정적 놀이신념은 유아교사 자신의 일반적 신념에 근거하여 이루어지며, 이러한 긍정적 놀이신념은 유 아의 놀이뿐 아니라 일상생활을 포함한 하루일과 전체에서 교사-유아의 상호작용에 영향을 줄 것으로 예상할 수 있다. 교사-유아의 상호작용은 교사와 유아의 만남과 헤어짐의 전 과정에서 관찰, 질문과 격려, 지지와 개입 등 유아의 사고를 다양하게 자극하는 방법에 의하여 유아의 발달에 기여하도 록 하므로 유아교사가 놀이의 가치와 중요성에 대해 보다 긍정적으로 인식하고 있는 것과 깊은 관련이 있을 것으로 예측된다. 영유아교사의 놀이신념이 영유아와의 긍정적인 상호작용 증진에 영향을 준다는 선행연구(Seo \& Lee, 2014; Yi \& Choi, 2013)들에 비추어 볼 때 유아교사의 긍정적 놀이 신념이 놀이뿐 아니라 일상생활에서의 교사-유아의 상호작 용에 영향을 미치는 중요한 선행변인인지를 확인해 볼 필요 가 있다.

이상의 유아교사의 놀이성, 긍정적 놀이신념, 교사-유아 
상호작용의 관계를 통해 볼 때 유아교사의 놀이성은 교사-유 아의 상호작용에 직접적인 영향을 미치기도 하지만 유아교 사의 놀이성이 긍정적 놀이신념 내면화에 영향을 미치고, 내 면화된 긍정적 놀이신념이 교사-유아의 상호작용에 영향을 미칠 것으로 예측해 볼 수 있다. 즉, 유아교사의 놀이성이 높 을수록 교사-유아의 상호작용은 높게 나타나는데, 높은 수준 의 유아교사의 놀이성은 긍정적 놀이신념을 형성하여 높은 수준의 교사-유아의 상호작용으로 그 영향을 미치게 될 것이 다. 이는 놀이성 수준이 높은 유아교사는 내적동기에 의해 유 아와의 놀이뿐 아니라 일상생활을 재미있는 놀이 같이 만들 어 상호작용 촉진자로서의 역할을 할 가능성이 존재하기 때 문이다. 또한 긍정적 놀이신념의 수준이 높은 유아교사는 교 수행동에 기초가 되는 유아교사의 일반적 신념에 근거하여 놀이에서의 상호작용뿐만 아니라 일상생활에서의 상호작용 에서도 지루하거나 무미건조한 상황을 즐겁게 만들고 긍정 적인 정서 경험을 할 가능성을 높일 것으로 기대할 수 있다.

따라서 이 연구에서는 유아교사의 놀이성 수준이 유아교 사의 긍정적 놀이신념에 영향을 미칠 것이며, 이러한 영향이 교사-유아의 상호작용에 영향을 미친다는 점을 매개효과를 통해서 검증하고자 한다. 이로써 유아교사의 놀이성과 긍정 적 놀이신념을 증진 시킬 수 있는 방안을 모색하는 기초자료 로 활용할 수 있을 것이며 나아가 교사교육을 위한 자료 제공 에 기여할 수 있을 것이다. 이를 위해 설정한 본 연구의 연구 문제와 연구모형은 다음의 Figure 1과 같다.

\section{연구문제 1}

유아교사의 놀이성, 긍정적 놀이신념 및 교사-유아의 상호작 용 간의 관계는 어떠한가?

\section{연구문제 2}

교사-유아의 상호작용에 대한 유아교사의 놀이성의 영향은 긍정적 놀이신념에 의해 매개되는가?

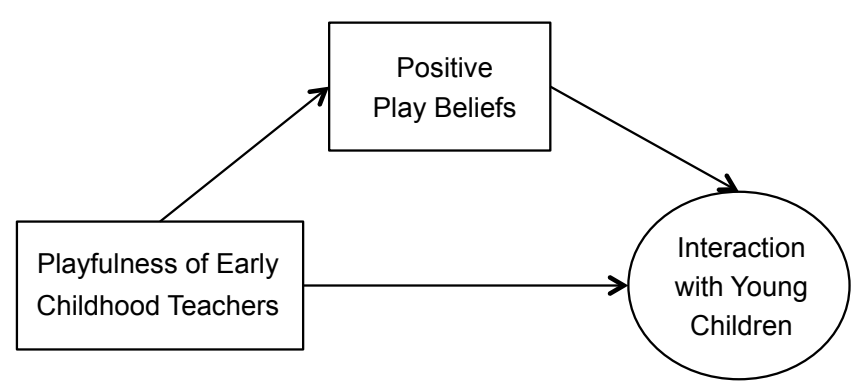

Figure 1. Hypothetical model.

\section{Methods}

\section{연구대상}

본 연구의 연구대상은 서울시에 근무하는 어린이집 105 개 기 관의 유아반 담임교사 269명이다. 연구대상의 일반적 특성을 살펴보면 Table 1 과 같다.

연구대상 유아교사들이 근무하고 있는 어린이집의 시설 유형은 국공립어린이집(56.9\%)이 가장 많았고, 민간어린이집 (24.9\%), 직장어린이집(18.2\%)의 순으로 나타났다. 담당유아의 연령은 만 3 세가 $39.8 \%$ 로 가장 많았고 만 4 세가 $36.0 \%$, 만 5세 가 $24.2 \%$ 로 순이었다. 보육경력은 5년 7년 미만(27.1\%)이 가 장 많았고, 7년 10년 미만이 22.7\%, 3년 5년 미만이 22.3\%로 나타났다. 최종학력은 2-3년제 전문대학 졸업자가 $39.4 \%$ 로 가 장 많았고 4년제 대학 졸업자가 $35.7 \%$, 대학원 이상의 학력 소 지자가 $17.5 \%$ 였다. 유아교사의 전공은 유아교육학 $(37.9 \%)$, 보 육학(22.7\%), 아동학(18.2\%)의 순으로 나타났다. 소지하고 있 는 자격 유형은 보육교사 1 급(56.9\%)이 가장 많았고, 유치원 2 급 정교사(27.1\%), 보육교사 2급(10.6\%)의 순이었다.

\section{연구도구}

\section{유아교사의 놀이성}

유아교사의 놀이성을 측정하기 위하여 Schaefer와 Greenberg (1997)에 의해 개발된 Playfulness Scale for Adults (PSA)를 Oh (2008)가 수정-보완하여 사용한 유아교사 놀이성 검사를 사 용하였다. 이 도구는 익살스러움(5문항), 유머감각(7문항), 재 미탐닉(6문항)의 3 개 영역 총 18 문항으로 구성되어 있다. 익살 스러움은 농담 혹은 재미있는 행동에 참여하는 성향을 의미하 며, "나는 친구들과 함께 있을 때, 주로 내가 먼저 재미있는 말 이나 행동을 한다.”와 같은 문항이다. 유머감각은 긍정적인 상 호작용을 통하여 즐거움을 주는 성향을 말하고, 문항의 예시 로는 “나는 되도록 많이 웃거나 미소 짓는 것을 좋아한다."와 같은 것이다. 재미탐닉은 상상력을 발휘하여 재미를 추구하는 상황을 만드는 성향을 의미하며, "나는 때때로 우스운 표정을 하거나 유치하게 행동하는 것을 즐긴다."와 같은 문항이다. 본 도구는 5점 Likert 척도로 평정되고 놀이성 전체를 살펴보기 위해 하위요인을 합산하여 사용하였으며 합산점수가 높을수 록 유아교사의 놀이성 수준이 높은 것을 의미한다. 놀이성 전 체 요인의 내적합치도(Cronbach's $\alpha$ )는 .89로 나타났다. 
Table 1

Descriptive Characteristics of the Participants

\begin{tabular}{|c|c|c|c|}
\hline \multicolumn{2}{|c|}{ Variables } & \multirow{2}{*}{$\begin{array}{c}n \\
153\end{array}$} & \multirow{2}{*}{$\begin{array}{c}\% \\
56.9\end{array}$} \\
\hline Type of child care center & National public childcare center & & \\
\hline & Workplace childcare center & 49 & 18.2 \\
\hline & Private childcare center & 67 & 24.9 \\
\hline \multirow[t]{3}{*}{ Age of class children } & 3 & 107 & 39.8 \\
\hline & 4 & 97 & 36.0 \\
\hline & 5 & 65 & 24.2 \\
\hline \multirow[t]{5}{*}{ Total working experience (years) } & Under 3 & 39 & 14.5 \\
\hline & $3-5$ & 60 & 22.3 \\
\hline & $5-7$ & 73 & 27.1 \\
\hline & $7-10$ & 61 & 22.7 \\
\hline & 10 and over & 36 & 13.4 \\
\hline \multirow[t]{4}{*}{ Education } & High school graduate & 20 & 7.4 \\
\hline & Two or three-year college graduate & 106 & 39.4 \\
\hline & Four-year university graduate & 96 & 35.7 \\
\hline & Master's degree or higher & 47 & 17.5 \\
\hline \multirow[t]{4}{*}{ Major } & Child studies & 49 & 18.2 \\
\hline & Early childhood education & 102 & 37.9 \\
\hline & Childcare & 61 & 22.7 \\
\hline & Other & 57 & 21.2 \\
\hline \multirow[t]{5}{*}{ Certification (multiple responses) } & A kindergarten first class teacher & 1 & 0.3 \\
\hline & A kindergarten second grade teacher & 107 & 27.1 \\
\hline & Childcare teacher level 1 & 225 & 56.9 \\
\hline & Childcare teacher level 2 & 42 & 10.6 \\
\hline & Other & 20 & 5.1 \\
\hline
\end{tabular}

Note. $N=269$.

\section{유아교사의 긍정적 놀이신념}

유아교사의 긍정적 놀이신념을 측정하기 위해 Fogle (2003)에 의해 제작된 the Parent Play Beliefs Scale (PPBS)를 번안한 You와 Yoo (2008)의 어머니 놀이신념 척도를 영유아기관 상황에 맞 게 수정한 척도로 측정되었다. You와 Yoo (2008)의 척도는 긍 정적 놀이신념과 부정적 놀이신념, 부모중심 놀이신념 3 개 요 인으로 구성되었는데 종속변인인 교사-유아의 상호작용은 교 사가 유아의 개별적 차이를 이해하고, 유아에게 발달적으로 적합한 경험을 제공하며 놀이를 포함하여 유아의 하루 일과활 동 전체에서 관찰, 지지와 개입 등으로 유아의 발달에 기여 하 도록 하는 것을 의미하므로 유아교사가 놀이의 가치와 중요 성을 긍정적으로 인식하는 것과 관련이 있을 것으로 예측되기 때문에 긍정적 놀이신념만을 연구도구로 사용하였다. 긍정적 놀이신념은 "놀이를 통해서 유아는 새로운 기술과 능력을 발
달시킨다.”, “놀이는 유아에게 무척 재미있는 활동이다.”와 같 은 놀이 활동을 통해 유아의 성장과 발달을 도모할 수 있다는 문항으로 구성되어 있다. 검사문항은 총 13 문항으로 구성되 었으며 Likert식 5점 척도를 사용하였다. 점수가 높을수록 유 아교사가 높은 수준의 긍정적 놀이신념을 가진 것으로 평가된 다. 본 연구의 내적합치도(Cronbach's $\alpha$ )는 .94이었다.

$$
\text { 교사-유아 상호작용 }
$$

교사-유아의 상호작용을 측정하기 위하여 J.-S. Lee (2003)가 the Assessment Profile for Early-Childhood Programs (APECP) 평 가척도, the National Childcare Accreditation Council (NCAC) 인정기준, the National Association for the Education of Young Children (NAEYC) 인정기준, 유아교육 프로그램 평가척도, 한 국 교육 개발원 평가 기준 등의 평가척도에서 문항을 추출하 
여 수정·보완한 교사-유아의 상호작용 평가척도를 본 연구에 서 사용하였다. 이 도구는 정서적 상호작용, 언어적 상호작용 및 행동적 상호작용 3 개 하위영역으로 각각 10 문항씩 총 30 문항으로 구성되어 있다. 정서적 상호작용은 교사가 유아의 개별적 감정에 반응해주고 유아의 생각과 느낌을 자유롭게 나눌 수 있도록 허용적인 분위기를 조성해 주는 것을 말한다. 문항의 예시로는 "유아의 다양한 정서표현에 대해 느낌을 존 중하고 민감하게 반응한다.”와 같은 것이다. 언어적 상호작용 은 교사가 유아의 질문이나 요구에 언어적으로 반응하는 것 을 의미하며, "유아의 의견을 존중하면서 의사소통을 시작하 고 유지한다."와 같은 문항이다. 행동적 상호작용은 교사의 신체적 표현을 통해 유아들이 긍정적으로 행동할 수 있도록 돕는 것을 말하며, "유아에게 안아주기 등 긍정적인 신체표현 을 자주한다.”와 같은 문항이다. 본 도구는 Likert식 5점 척도 로 총점이 높을수록 교사-유아의 상호작용 수준이 높은 것이 고, 점수가 낮을수록 교사-유아의 상호작용 수준이 낮음을 의 미한다. 각 하위요인의 내적합치도(Cronbach's $\alpha$ )는 정서적 상호작용 .91, 언어적 상호작용 .91, 행동적 상호작용 .90으로 높은 수준이었다.

\section{연구절차}

\section{예비조사}

본 조사에 앞서 검사도구인 유아교사의 놀이성, 긍정적 놀이 신념, 교사-유아 상호작용의 문항내용 적절성 및 이해도, 검사 소요시간 및 문제점 확인을 위하여 2018년 4월 20일부터 4월 27일 사이에 예비조사를 실시하였다. 본 조사에 포함되지 않 은 서울시의 국공립 어린이집에서 근무하는 유아교사 51인을 대상으로 사전 설명 후 동의를 구하고 직접 설문에 응답할 수 있도록 하였다. 예비조사 결과, 문항 이해에 어려움이 없었으 며 연구절차상의 문제도 없음이 확인되었다.

\section{본 조사}

본 조사는 2018년 8월 3일부터 2018년 8월 31일까지 조사 대 상이 된 서울 소재의 어린이집 105 개소의 유아교사를 대상으 로 설문지를 배부하여 진행하였다. 설문지는 연구자가 어린이 집을 직접 방문하여 원장과 유아교사에게 연구의 목적과 질문 응답 방법을 설명한 후 유아교사들이 직접 응답하도록 하였으 며 1 주의 여유를 두고 연구자가 어린이집을 재방문하여 회수
하였다. 처음 배포된 설문지는 289 부였으며, 회수된 285 부 중 중복응답이나 무응답 항목이 포함된 자료 16 부를 제외하고 총 269부가 최종 자료 분석에 사용되었다.

\section{자료분석}

본 연구를 위해 수집된 자료는 SPSS 21.0 (IBM Co., Armonk, $\mathrm{NY}$ )과 SPSS Amos 21.0 (IBM Co., Armonk, NY) 프로그램 을 사용하여 분석하였다. 측정도구의 신뢰도 확인을 위하여 Cronbach's $\alpha$ 계수를 산출하고, 연구 대상의 인구통계학적 특 성을 살펴보기 위해 빈도분석, 기술통계를 실시하였다. 측정 변인들 간의 관계 파악을 위해 Pearson 상관관계분석을 실시 하고, 주요 변인들 간의 구조적인 관계를 살펴보기 위해 구조 방정식모형(structural equation modeling) 분석을 실시하였다. 연구문제에 제시된 매개효과 분석을 위해 간접효과 분석에 효 과적인 부트스트래핑(bootstrapping) 방식을 적용하여 분석하 였다(Bollen \& Stine, 1992). 모형의 평가를 위한 적합도 지수로 는 절대 적합지수(absolute fit index)로 $\chi^{2}$ (CMIN)과 Root Mean Square Error of Approximation (RMSEA)를 사용하였고, 증분적 합지수(increm-ental fit index)로는 Tucker-Lewis Index (TLI)와 Comparative Fit Index (CFI)를 평가에 적용하였다.

\section{Results}

연구결과의 제시에 앞서 각 변인들의 일반적 경향을 알아보기 위해 기술통계치와 Person의 상관계수를 제시하면 Table 2 와 같다.

\section{유아교사의 놀이성과 긍정적 놀이신념, 교사- 유아 상호작용의 기술통계와 상관관계}

유아교사의 놀이성, 긍정적 놀이신념 및 교사-유아 상호작용 의 기술적인 통계를 살펴보면, 유아교사의 놀이성 평균은 5점 기준으로 할 때 평균 3.67점으로 보통보다 높은 수준이었으며 유아교사의 긍정적 놀이신념의 평균은 5점 기준 4.53점으로 높게 나타났다. 교사-유아의 상호작용의 평균은 하위 영역별 로 나누어 보면 5점 기준으로 정서적 상호작용이 4.29점으로 가장 높았고, 행동적 상호작용은 4.22점, 언어적 상호작용은 4.21점으로 높게 나타났다.

변인들 간의 상관관계를 살펴보면, 유아교사의 놀이성은 
Table 2

Means, Standard Deviations, and Correlations Among Variables

\begin{tabular}{lccccc}
\hline \multicolumn{1}{c}{ Variables } & 1 & 2 & 3 & 4 & 5 \\
\hline 1. Playfulness & - & & & & \\
2. Positive play beliefs & $.409^{* *}$ & - & & & \\
3. Emotional interaction & $.536^{* *}$ & $.483^{* *}$ & - & & \\
4. Linguistic interaction & $.503^{* *}$ & $.512^{* *}$ & $.911^{* *}$ & - &. \\
5. Behavioral interaction & $.517^{* *}$ & $.493^{* *}$ & $.907^{* *}$ & $.899^{* *}$ & - \\
$M$ & 3.67 & 4.53 & 4.29 & 4.21 & 4.22 \\
$S D$ & .578 & .508 & .504 & .526 & .509 \\
\hline
\end{tabular}

Note. $N=269$.

${ }^{* *} p<.01$.

Table 3

Goodness of Fit of the Mediation Model

\begin{tabular}{ccccc}
\hline$\chi^{2}$ & $d f$ & TLI & CFI & RMSEA \\
\hline 5.072 & 4 & .998 & .999 & .032 \\
\hline
\end{tabular}

긍정적 놀이신념과 유의한 정적 상관 $(r=.409, p<.01)$ 이 나타 났고, 교사-유아 상호작용의 하위영역인 정서적, 언어적 및 행 동적 상호작용과 정적 상관 $(r=.536, p<.01 ; r=.503, p<.01 ; r$ $=.517, p<.01)$ 이 나타났다. 긍정적 놀이신념은 교사-유아 상 호작용의 하위영역인 정서적, 언어적 및 행동적 상호작용과 정적 상관 $(r=.483, p<.01 ; r=.512, p<.01 ; r=.493, p<.01)$ 이 나타났다.

\section{유아교사의 놀이성과 교사-유아의 상호작 용에 미치는 영향에 대한 긍정적 놀이신념의 매개효과}

유아교사의 놀이성이 긍정적 놀이신념을 통해 교사-유아의 상호작용에 미치는 영향을 살펴보기 위해 모형의 적합도 검 증을 실시하였다. 그 결과, 연구모형의 적합도 지수들은 $\chi^{2}=$ $5.072(p=.280), \mathrm{TLI}=.998, \mathrm{CFI}=.999, \mathrm{RMSEA}=.032$ 로 매 우 양호한 수준으로 나타나, 본 연구모형이 분석에 적합한 것 으로 밝혀졌다(Table 3).

모형에서 유의미하게 밝혀진 경로를 살펴보면, 유아교사 의 놀이성은 교사-유아 상호작용의 하위영역인 정서적, 언어 적 및 행동적 상호작용 $(\beta=.406, p<.001 ; \beta=.352, p<.001 ; \beta$ $=.379, p<.001)$ 에 정적 영향을 미치는 것으로 나타났으며, 유 아교사의 놀이성은 긍정적 놀이신념 $(\beta=.409, p<.001)$ 을 통 해 정서적 상호작용 $(\beta=.316, p<.001)$ 과 언어적 상호작용 $(\beta=$
$.368, p<.001)$, 행동적 상호작용 $(\beta=.338, p<.001)$ 에 유의한 정적 영향을 미치는 것으로 나타났다. 즉, 유아교사의 놀이성 은 긍정적 놀이신념이 높을수록 정서적, 언어적 및 행동적 상 호작용의 수준도 높은 것으로 나타남과 동시에, 유아교사의 높은 놀이성 수준은 높은 긍정적 놀이신념으로 이어져 교사유아의 상호작용 수준을 높이는 간접적인 경로가 밝혀졌다.

이러한 결과를 토대로 유아교사의 놀이성은 교사-유아 상 호작용에 직접적인 영향을 미칠 뿐만 아니라, 긍정적 놀이신 념을 통해 유아와의 높은 수준의 상호작용을 시도 할 수 있음 을 알 수 있다. 해당 모형의 구체적인 경로계수는 다음의 Table 4에 제시된 바와 같다.

마지막으로 유아교사의 놀이성이 교사-유아의 정서적, 언어 적 및 행동적 상호작용에 미치는 간접효과의 유의성을 검증하 기 위해 부트스트래핑(bias corrected bootstrapping) 검증을 실시 하였다(Table 5). 그 결과 유아교사의 놀이성이 교사-유아의 상 호작용에 미치는 간접효과는 정서적 상호작용 .129 , 언어적 상 호작용 .151, 행동적 상호작용 .138로 $p<.001$ 수준에서 통계적 으로 유의미한 것으로 나타났다. 또한 $95 \%$ 신뢰구간의 상한 값과 하한 값이 정서적 상호작용은 .078 .189, 언어적 상호작 용은 .096 .211, 그리고 행동적 상호작용은 .091 .191로 0이 포함되지 않아 정적인 영향력으로 보는 데에 어려움이 없는 것 으로 나타났다. 즉, 유아교사의 놀이성의 수준이 높을수록 긍 정적 놀이신념이 높아져, 높은 수준의 교사-유아의 정서적, 언 어적 및 행동적 상호작용이 나타날 것이라는 가설이 지지되었 
Table 4

Parameter Estimates of Final Model

\begin{tabular}{llllll}
\hline & & Paths & $B$ & & $S E$ \\
Playfulness & $\rightarrow$ & Positive play beliefs & .359 & .049 & $.409^{* * *}$ \\
Playfulness & $\rightarrow$ & Emotional interaction & .354 & .046 & $.406^{* * *}$ \\
Playfulness & $\rightarrow$ & Linguistic interaction & .32 & .048 & $.352^{* * *}$ \\
Playfulness & $\rightarrow$ & Behavioral interaction & .333 & .047 & $.379^{* * *}$ \\
Positive play beliefs & $\rightarrow$ & Emotional interaction & .314 & .053 & $.316^{* * *}$ \\
Positive play beliefs & $\rightarrow$ & Linguistic interaction & .382 & .055 & $.368^{* * *}$ \\
Positive play beliefs & $\rightarrow$ & Behavioral interaction & .339 & .054 & $.338^{* * *}$ \\
\hline
\end{tabular}

${ }^{* * *} p<.001$.

Table 5

Direct, Indirect, and Total Effects of Model

\begin{tabular}{llcccccc}
\hline & & & & & \multicolumn{3}{c}{$95 \%$ BC of indirect effect } \\
& & Paths & Direct effect & Indirect effect & Totel effect & Lower & Upper \\
\hline Playfulness & $\rightarrow$ & Emotional interaction & $.406^{* * *}$ & $.129^{* * *}$ & $.536^{* * *}$ & .078 & .189 \\
Playfulness & $\rightarrow$ & Linguistic interaction & $.352^{* * *}$ & $.151^{* * *}$ & $.503^{* * *}$ & .096 & .211 \\
Playfulness & $\rightarrow$ & Behavioral interaction & $.379^{* * *}$ & $.138^{* * *}$ & $.517^{* * *}$ & .091 & .191 \\
\hline
\end{tabular}

${ }^{* * *} p<.001$.

다.

\section{Discussion}

본 연구는 유아교사의 놀이성과 긍정적 놀이신념, 교사-유아 의 상호작용의 관계를 살펴보고, 유아교사의 놀이성이 교사유아의 상호작용에 미치는 영향에 대하여 긍정적 놀이신념의 매개역할을 알아보고자 하였다. 본 목적을 수행하기 위해 서 울시에 근무하는 어린이집 유아교사 269명을 대상으로 질문 지 조사법을 사용하여 유아교사의 놀이성, 긍정적 놀이신념, 교사-유아의 상호작용을 측정하였다. 그 결과, 유아교사의 놀 이성, 긍정적 놀이신념, 교사-유아의 상호작용 간 모두 유의 한 정적 상관관계를 보였으며, 유아교사의 놀이성은 교사-유 아의 상호작용에 직접적인 영향을 미치고, 긍정적 놀이신념 을 통해 교사-유아의 상호작용에 간접적인 영향을 미치는 것 으로 나타나, 긍정적 놀이신념이 매개변인으로서 역할을 함이 밝혀졌다. 분석된 연구 자료를 토대로 다음과 같은 결론을 도 출하였다.

첫째, 유아교사의 놀이성, 긍정적 놀이신념, 교사-유아 상 호작용 간에는 서로 정적인 관계가 있는 것으로 나타났다. 이 는 유아와의 놀이뿐 아니라 일상생활에서 유아교사의 놀이성 수준이 높을수록 긍정적 놀이신념, 교사-유아 상호작용의 수 준이 높게 나타나며, 유아교사의 긍정적 놀이신념, 교사-유아
상호작용 간에도 서로 관련성이 있음을 의미한다. 이러한 결 과는 유아교사의 놀이성이 놀이신념, 놀이교수효능감과 정적 인 상관이 있음을 밝힌 연구(Kwon, 2012)와 일관된 것이며 교 사의 놀이신념과 행동이 유아의 발달에 미치는 정적 관련성을 갖는 것으로 나타난 연구결과(E. Shin \& Park, 2006; Yu \& Shin, 2005)를 지지하는 것이다. 즉, 유아교사 자신이 유아와의 놀이 뿐 아니라 일상생활에서 놀이의 가치와 중요성을 인식하고, 놀이에 대한 긍정적 신념이 강할수록 유아와의 정서적, 언어 적 및 행동적 상호작용에 더욱 적극적으로 행동하게 되는 것 으로 추론해 볼 수 있다.

둘째, 유아교사의 놀이성은 긍정적 놀이신념을 매개로 교 사-유아의 정서적, 언어적 및 행동적 상호작용에 직·간접의 영 향을 미치는 것으로 나타났다.

먼저, 유아교사의 놀이성이 긍정적 놀이신념에 유의한 영 향을 미치는 것으로 나타나, 놀이행동에 대한 자발적인 내적 동기가 유아교사의 긍정적 놀이신념에 중요한 역할을 하는 것 을 확인할 수 있었다. 유아교사가 긍정적 놀이신념을 갖는다 는 것은 유아에게 있어서 놀이가 즐거운 활동이고, 유아는 놀 이를 통해 새로운 학습과 경험을 이끌어 간다는 일반적 신념 을 갖고 있음을 의미한다고 볼 수 있다. 놀이성이 높은 사람은 새로운 경험에 개방적이며, 자신이 원하는 내적으로 동기화된 활동을 할 수 있고 그에 따른 만족감과 즐거움을 경험할 가능 
성이 크다(Schaefer \& Greenberg, 1997)고 알려져 있다. 이러한 성향은 내적동기, 즐거움, 자유로운 선택, 능동적 참여 등 놀이 의 특성과 그 흐름을 같이 하므로 놀이성이 높은 유아교사가 놀이의 가치와 중요성에 대해 보다 긍정적인 놀이신념을 형성 한다고 해석할 수 있다. 이는 놀이성이 전 생애에 걸쳐 드러나 는 내적 특성이며 삶을 영위하는데 매우 중요한 요소이기 때 문에 다양한 행동의 결과들을 예측할 수 있는 선행변인으로 작용한다(Huizinga, 1938/2010)는 연구결과와 같은 맥락으로 유아교사의 놀이성과 긍정적 놀이신념의 역할이 이해될 수 있 다. 또한 유아교사의 놀이성을 통해 긍정적인 놀이신념을 갖 는다는 것은 교사로서 중요한 자질의 향상을 증진 시킬 수 있 다는(Pajares, 1992) 연구결과에 비추어 볼 때, 유아교사의 놀이 성이 긍정적 놀이신념에 유의미한 영향을 주고 있음을 보여주 고 있다. 놀이성이 높은 유아교사는 유아와의 활동에서 즐거 움, 재미를 경험하고 이러한 경험들이 유아와의 활동에 적절 하게 개입하고 참여하여 긍정적인 영향을 줄 수 있다는 놀이 신념을 형성하도록 하는 것이다. 교사가 유아와의 활동에 즐 거움을 느끼는 것이 교수활동에 긍정적인 영향(Jarrett, 1998) 을 준다고 할 수 있다.

다음으로, 유아교사의 긍정적 놀이신념은 유아의 놀이뿐 아니라 일상생활을 포함한 하루일과 전체에서 교사-유아의 정서적, 언어적 및 행동적 상호작용에 정적 영향을 미치는 것 으로 나타났다. 즉, 긍정적 놀이신념 수준이 높은 유아교사는 놀이의 교육적 가치를 교사 자신의 일반적 신념으로 삼고 있 어, 유아와의 놀이뿐 아니라 일과활동 안에서 따뜻하고 반응 적이고 유아의 의견을 존중해 준다고 해석할 수 있다. 또한 불 안과 같은 부정적인 유아의 감정을 쉽게 파악하고 이를 다시 긍정적인 감정으로 제공하여 유아가 즐거운 감정으로 놀이뿐 아니라 일과활동에 참여 할 수 있도록 정서적 상호작용을 시 도한다고 해석할 수 있다. 뿐만 아니라 높은 수준의 긍정적 놀 이신념을 가진 유아교사는 유아가 잘 놀기 위해 다른 사람의 말과 행동에 관심을 가져야 하고, 분명한 의사소통을 위해 유 아 자신의 언어사용에 집중해야 한다는 것을 인식하고 있어, 유아가 따분하거나 재미없다고 느끼는 놀이뿐 아니라 일과활 동 상황도 우스운 이야기로 만드는 언어적 상호작용을 시도하 여 유아가 다른 사람과 언어를 공유하고 합의하는 경험을 할 수 있도록 지원한다고 해석할 수 있다. 더불어 긍정적 놀이신 념이 높은 유아교사는 유아의 신체발달과 관련된 표현들을 이 해하고 있어 유아가 놀이뿐 아니라 일과활동을 통해 자신의 욕구를 조절하여 적절한 행동을 경험할 수 있도록 도우며, 유 아와의 모호한 상황도 행동적 상호작용을 통해 유아가 자신의
신체적 자아개념을 탐색하고 성립해 나갈 수 있도록 지원한다 고 해석할 수 있다. 이러한 결과는 놀이에서 교사의 역할 및 행 동은 교사의 일반적 신념에 기초하여 구체적으로 진행된다고 설명하고, 놀이신념과 교사-영유아 상호작용의 관련성을 밝 힌 연구결과(Seo \& Lee, 2014; Stipek \& Byler, 1997; Yi \& Choi, 2013)를 지지한다. 또한 교사의 긍정적 놀이신념과 행동이 유 아의 발달에 긍정적인 영향력을 갖는 것으로 나타난 연구결과 (E. Shin \& Park, 2006; Yu \& Shin, 2005)와도 같은 맥락으로 볼 수 있다. 이는 긍정적 놀이신념의 수준이 높은 유아교사는 교 수행동에 기초가 되는 유아교사의 일반적 신념에 근거하여, 놀이에서 뿐만 아니라 일상생활의 정서적, 언어적 및 행동적 상호작용에서 지루하거나 무미건조한 상황을 즐겁게 만들고 긍정적인 경험을 시도 할 가능성이 높다고 볼 수 있다.

한편, 유아교사의 놀이성은 교사-유아의 정서적, 언어적 및 행동적 상호작용에 직접적으로 영향을 미치는 것으로 나타났 다. 즉, 놀이성 수준이 높은 유아교사는 유아가 재미있어 하 는 놀이나 일과활동에 똑같이 재미를 느낄 수 있고 공감대 형 성을 쉽게 하며, 놀이뿐 아니라 일과활동 안에서 유아가 자신 의 정서를 마음껏 표출 할 수 있도록 정서적 상호작용을 시도 한다고 해석할 수 있다. 또한 높은 수준의 놀이성을 가진 유아 교사는 유아와의 놀이뿐 아니라 일상생활의 다양한 경험을 통 해 유아가 언어 및 의사소통 능력을 기르고 유아만의 유용한 아이디어를 만들어 내어 맞닥뜨린 문제를 스스로 해결해 나 갈 수 있도록 언어적 상호작용을 시도한다고 해석할 수 있다. 이와 함께 놀이성이 높은 유아교사는 유아의 신체발달과 관련 된 다양한 표현들을 이해하고, 움직임의 모델이 되기도 하며 유아가 놀이 및 일상생활에서 신체적 능력과 한계를 알고 행 동조절 방법 등을 익힐 수 있도록 행동적 상호작용을 지원한 다고 해석할 수 있다. 이러한 결과는 놀이성이 높은 사람이 주 어진 일이나 활동을 보다 즐기면서 수행하는 성향이 있으며 (Schaefer \& Greenberg, 1997), 이러한 성향이 업무수행에 잠재 적인 영향을 주고 보다 나은 결과를 이끌도록 한다(Spaulding, 2010)는 연구결과를 지지한다. 덧붙여 교사의 놀이성이 유아 의 문제행동지도전략(Kwon, 2013)이나 음률지도의 적극성(I. Lee \& Lee, 2016; H. Lim \& Bang, 2017)과 같은 교수행동에 긍 정적으로 작용했다는 선행연구와 연결 지어 생각해 볼 때, 놀 이성이 높은 유아교사는 유아의 성장, 발달과 보육의 질 향상 을 위해 유아와 긍정적으로 정서적, 언어적 및 행동적 상호 작용을 시도한다(Trawick-Smith \& Dziurgot, 2011)고 이해될 수 있다. 놀이성이 풍부한 유아교사는 유아와의 놀이뿐 아니 라 일상생활에서 자유로운 선택의 기회를 나누고, 재미있거 
나 우스운 것, 엉뚱한 것을 수용하는 등 민감한 정서적, 언어적 및 행동적 상호작용을 시도한다고 볼 수 있다. 교사가 유아와 의 놀이 및 일상생활을 포함한 하루일과 전체에서 주어진 상 황을 재미있는 놀이와 같이 즐기고자 하는 성향을 가지는 것 이 유아교사가 상호작용자로서의 역할을 더 잘 수행할 수 있 도록 하는 것이다. 이는 자신의 일을 즐기는 것이 높은 수준의 일의 수행능력 향상으로 연결될 수 있기 때문이다(Brown \& Vaughan, 2009).

마지막으로, 본 연구에서는 유아교사의 놀이성이 높을수 록 긍정적 놀이신념이 높았고, 긍정적 놀이신념이 높을수록 교사-유아 상호작용의 수준도 높아짐을 검증하여 유아교사의 놀이성이 교사-유아 상호작용에 직·간접적 효과를 갖는 영향 력 있는 변인임이 밝혀졌다. 이러한 결과는 영유아교사의 놀 이성이 영유아에 대한 적극적, 반응적 교수행동을 이끌어낸다 는 선행연구(Kwon, 2012; I. Lee \& Lee, 2016; H. Lim \& Bang, 2017)를 지지하는 것이며, 영유아교사의 교수 적극성은 이에 대한 긍정적인 놀이신념이 발휘될수록 더욱 높아진다는 앞선 연구결과(Fogle, 2003; Kwon, 2013; Seo \& Lee, 2014; Yi \& Choi, 2013)와 일관되는 결과라 할 수 있다. 본 연구의 결과는 긍정 적 놀이신념이나 교사-유아의 정서적, 언어적 및 행동적 상호 작용을 제고시키기 위해서는 먼저 유아교사가 자신의 즐거움 을 자연스럽게 표출하고 이를 유아와의 놀이뿐 아니라 일상 생활의 상호작용 과정에 연결시킬 수 있도록 할 필요가 있음 을 나타낸다. 놀이성은 내적 성향이라는 개인적 특성의 의미 를 갖고 있으나 환경이나 경험에 의해 영향을 받는다고(J. Y. $\mathrm{Kim}, 2007)$ 보고되고 있다. 즉, 긍정적 놀이신념이나 교사-유 아의 정서적, 언어적 및 행동적 상호작용은 놀이성이 환경이 나 경험에 의해 재형성 및 변화가 가능하다는 점을 증거로 유 아와의 하루 일과활동 중 유아교사가 자신의 즐거움을 자유롭 게 표현하는 자발적인 동기를 갖도록 지원함으로써 보다 증대 될 수 있다는 것을 보여준다.

아울러 본 연구의 주요 결과를 바탕으로 볼 때, 놀이뿐 아니 라 일상생활에서 교사-유아의 정서적, 언어적 및 행동적 상호 작용의 수준을 높이려면 유아교사의 놀이성 지원과 함께 긍정 적 놀이신념을 계발하는 것이 유아교사의 놀이성과 교사-유 아의 상호작용을 연계하는 효과적인 방안임을 알 수 있다. 놀 이에 대한 의사결정이 교사 자신의 놀이에 대해 가지고 있는 신념에 근거하여 이루어지고(Stipek \& Byler, 1997), 이러한 구 체적인 신념이 적극적인 교수행동에 영향을 준다(Fogle, 2003) 는 점을 감안할 때 지속적인 교사교육과 실행을 통해 놀이의 중요성과 가치, 의미를 내면화하여 긍정적 놀이신념을 갖도록
하는 것이 중요하다. 놀이성이 낮은 교사들도 교사교육을 통 해 긍정적 놀이신념을 형성하고 증진시키게 된다면 이들이 유 아와의 놀이에서뿐 아니라 일상생활에서 더욱 적극적인 정서 적, 언어적 및 행동적 상호작용을 시도할 수 있을 것이다. 따라 서 예비교사나 현직교사를 위한 교사교육 내용에 놀이뿐 아니 라 일상생활에서 놀이의 가치는 물론 교사 역할의 중요성을 인식시키고 이를 유아와의 하루일과 전체에 있어서 보다 적극 적으로 발휘할 수 있도록 반영할 필요가 있다. 이를 위해 긍정 적 놀이신념을 증진시킬 수 있는 교사연수 지원은 물론 어린 이집에서 자체적으로 유아교사의 긍정적 놀이신념을 위한 향 상 방안을 마련할 필요가 있을 것이다.

본 연구의 제한점을 바탕으로 추후 연구의 방향성을 제안 하면 다음과 같다. 첫째, 본 연구는 서울시에 위치한 어린이집 에 근무 중인 유아교사를 대상으로 국한하였고, 경력이 짧은 유아교사들이 포함되었으며, 유아교사와 유아의 환경적인 요 인들을 포함하지 못하여 연구결과를 일반화하는데 한계가 있 다. 향후 다양한 지역에서 연구대상을 표집하고, 유아교사 그 룹 구분의 근거를 더 명확히 하여 유아교사와 유아를 둘러싼 환경적인 변인을 고려한 후속연구가 필요할 것으로 본다. 둘 째, 질문지 조사법을 사용한 본 연구는 어린이집 일과활동의 실제를 유아교사를 통해 살펴보고자 하여 유아교사의 놀이성, 긍정적 놀이신념, 교사-유아의 상호작용을 모두 유아교사의 인식에 따라 측정하였으므로 주관적인 편의 가능성이 있다. 특히 유아교사의 긍정적 놀이신념의 경우 평균이 4.53점으로 높게 나타났다. 이는 우리나라 국가수준의 표준보육과정인 누 리과정이 유아의 발달과 학습에서 놀이의 중요성과 가치를 강 조하고, 놀이중심 보육과정의 실천을 지지하여 놀이의 중요성 이나 긍정적 놀이신념, 교사-유아 상호작용에 관한 교사교육 및 장학이 이루어져 유아교사의 의식수준이 향상되었기 때문 이라고 볼 수 있다. 따라서 후속 연구에서는 측정방법의 타당 성을 높이기 위해 객관적 관찰평정 도구나 기관평가 자료 등 을 살펴보는 방법을 고려하는 것이 필요하다. 또한 본 연구는 횡단적인 접근 방식으로 이루어져 변인 간 인과성의 선행구조 파악에 한계가 있을 수 있어 추후 연구에서는 유아교사의 놀 이성, 긍정적 놀이신념, 교사-유아 상호작용 간의 시간적 특성 을 반영한 종단적인 방식으로 검증해 보는 노력이 필요하다.

이러한 제한점에도 불구하고 본 연구는 어린이집 하루일 과 전체를 교사-유아 상호작용의 관점에서 살피면서 교사-유 아의 상호작용에 영향을 미치는 변인으로 유아교사의 놀이성, 긍정적 놀이신념과 같은 유아교사 개인의 내적 특성에 주목하 여 그 관계를 분석해 보고자 하였다는 데 그 의미를 부여할 수 
있다. 또한 긍정적 놀이신념의 매개효과를 밝혀 교사-유아의 상호작용을 향상시킬 수 있는 구체적인 교사교육의 방향을 제 시하고 교사교육프로그램 개발을 위한 관련 기초자료를 제공 하였다는 측면에서 그 의의를 갖는다.

\section{Acknowledgements}

This study was supported by the 2018 research grant of Sangmyung University.

\section{Notes}

This article was presented at the Autumn Conference of the Korean Association of Child Studies in 2018.

\section{Conflict of Interest}

No potential conflict of interest relevant to this article was reported.

\section{References}

\section{In English}

Barnett, L. A. (2007). The nature of playfulness in young adults. Personality and Individual Differences, 43(4), 949-958. doi:10.1016/j.paid.2007.02.018

Bollen, K. A., \& Stine, R. A. (1992). Bootstrapping goodness-of-fit measures in structural equation models. Sociological Methods \& Research, 21(2), 205-229. doi:10.1177/0049124192021002004

Brown, S., \& Vaughan, C. (2009). Play: How it shapes the brain, opens the imagination, and invigorates the soul. New York: Penguin Group.

Dickinson, D. K., Darrow, C. L., \& Tinubu, T. A. (2008). Patterns of teacher-child conversations in Head Start classrooms: Implications for an empirically grounded approach to professional development. Early Education and Development, 19(3), 396-429. doi:10.1080/10409280802065403

Downer, J., Sabol, T. J., \& Hamre, B. (2010). Teacher-child interactions in the classroom: Toward a theory of withinand cross-domain links to children's developmental outcomes. Early Education and Development, 21(5), 699723. doi:10.1080/10409289.2010.497453

de Kruif, R. E. L., McWilliam, R. A., Ridley, S. M., \& Wakely, M. B. (2000). Classification of teacher's interaction behaviors in early childhood classroom. Early Childhood Research Quarterly, 15(2), 247-268. doi:10.1016/S08852006(00)00051-X

Fogle, L. (2003). Parent beliefs about play: Relations with parent-child play interactions and child peer play competence (Doctoral dissertation). Retrieved from https://search.proquest.com

Froebel, F. (1887). The education of man. New York: Appleton.

Glynn, M. A., \& Webster, J. (1992). The adult playfulness scale: An initial assessment. Psychological Reports, 71(1), 83-103. doi:10.2466/pr0.1992.71.1.83

Guitard, P., Ferland, F., \& Dutil, É. (2005). Toward a better understanding of playfulness in adults. OTJR: Occupation, Participation and Health, 25(1), 9-22. doi:10.1177/153944920 502500103

Jarrett, O. S. (1998). Playfulness: A motivator in elementary science teacher preparation. School Science and Mathematics, 98(4), 181-187. doi:10.1111/j.1949-8594.1998.tb17414.x

Leflot, G., Onghena, P., \& Colpin, H. (2010). Teacher-child interactions: Relations with children's self-concept in second grade. Infant and Child Development, 19(4), 385405. doi:10.1002/icd.672

Pajares, M. F. (1992). Teachers' beliefs and educational research: Cleaning up a messy construct. Review of Educational Research, 62(3), 307-332. doi:10.3102/00346543062003307

Robinson, H. F., \& Schwartz, S. L. (1982). Designing curriculum for early childhood. Boston, MA: Allyn \& Bacon.

Schaefer, C., \& Greenberg, R. (1997). Measurement of playfulness: A neglected therapist variable. International Journal of Play Therapy, 6(2), 21-31. doi:10.1037/h0089406

Sigel, I. E. (1992). The belief-behavior connection: A resolvable dilemma. In I. E. Sigel., A. V. McGillicuddy-DeLisi, \& J. J. Goodnow (Eds.), Parental belief systems: The psychological consequences for children (2nd ed., pp. 433-456). Hillsdale, NJ: Lawrence Erlbaum Associates.

Spaulding, J. T. (2010). The effects of experiential learning with playfulness in the adult education classroom (Doctoral dissertation). Retrieved from https://search.proquest.com

Spodek, B. (1985). Teaching in the early years (3rd ed.). Englewood Cliffs, NJ: Prentice-Hall.

Spodek, B., \& Rucinski, E. A. (1984, April). A study of early childhood teacher beliefs: Primary teachers. Paper presented at the annual meeting of the American Educational Research Association, New Orleans, LA, US.

Stipek, D. J., \& Byler, P. (1997). Early childhood education teachers: Do they practice what they preach? Early Childhood Research Quarterly, 12(3), 305-325. doi:10.1016/ 


\section{S0885-2006(97)90005-3}

Trawick-Smith, J., \& Dziurgot, T. (2011). 'Good-fit' teacher-child play interactions and the subsequent autonomous play of preschool children. Early Childhood Research Quarterly, 26(1), 110-123. doi:10.1016/j.ecresq.2010.04.005

Vandell, D. L. (2004). Early child care: The known and unknown. Merrill Palmer Quarterly, 50(3), 387-414. doi:10.1353/ mpq.2004.0027

\section{In Korean}

Cho, B. K., Go, Y. M., \& Park, G. H. (2003). The influence of self-concept on kindergarten teachers' job satisfaction. Korean Journal of Child Studies, 24(6), 81-94.

Cho, H. J., \& Kim, N. S. (2007). The relationships between toddlers' social-cognitive play behaviors and the environmental variables of play materials and teachers' interaction. Korean Journal of Early Childhood Education, 27(1), 199-219. doi:10.18023/kjece.2007.27.1.008

Choi, J.-S., \& Kim, H.-S. (2014). Kindergarten teacher job satisfaction: Self-consciousness and job stress as predictors. The Journal of Korea Open Association for Early Childhood Education, 19(5), 387-404.

Choi, M. S., \& Hwang, Y. S. (2007). The relationship between interactive peer play, teacher-child relation, and peer competence of young children. Journal of Future Early Childhood Education, 14(1), 103-123.

Chung, M. R., Lee, M. N., \& Kang, S. K. (2016). A mediating effect of self-directed learning and awareness of professionalism on the relationship between the professional learning environment and teacher-child interaction. The Journal of Korean Teacher Education, 33(1), 1-27. doi:10.24211/ tjkte.2016.33.1.1

Dan, H. K. (2011). Teacher's perception on the teacher-child relationships and children's peer competences. Korean Journal of Early Childhood Education, 13(2), 5-33.

Han, E., \& Huh, H. (2016). A study on influences of teacherchild interaction and teacher's efficacy on peer interaction. Korean Journal of Early Childhood Education, 36(2), 53-70. doi:10.18023/kjece.2016.36.2.003

Huizinga, J. (2010). Homo ludens (J. Lee, Trans.). Seoul: Yeounamseoga. (Original work published 1938)

Kim, H.-C. (2008). Analysis of debates on expertise of early childhood teachers. The Journal of Korea Open Association for Early Childhood Education, 13(5), 197-221.

Kim, J. Y. (2007). A study on the effect of father's playfulness with his child in early childhood to father's rearing behavior (Master's thesis). Retrieved from http://www.riss.kr/link?id= T10989728

Kim, M. J. (2013). The relationship between teacher-child relationship perceived by teacher and social competence of young children. Korean Journal of Early Childhood Education, 15(1), 137-163.

Kim, S., \& Kim, K. (2006). The effectiveness of reflective clinical supervision on children's interactions and teacher's teaching abilities in preschool. The Journal of Korea Open Association for Early Childhood Education, 11(4), 61-78.

Kwon, H. J. (2012). The mediating effect of teachers' positive beliefs about children's play on the relationship between playfulness in teachers and teaching efficacy on children's play. Korean Journal of Child Studies, 33(6), 133-147. doi:10.5723/KJCS.2012.33.6.133

Kwon, H. J. (2013). The effects of early childhood teachers'playfulness, teachers'positive play beliefs and teaching efficacy on play on teachers' strategies of problem behavior guidance. Journal of Korean Child Care and Education, 9(1), 175-200.

Lee, H., Jo, H.-B., \& Lee, Y.-J. (2010). Development of adult playfulness scale. Journal of Tourism Sciences, 34(9), 165188.

Lee, I., \& Lee, W. (2016). Child care teachers' playfulness and teaching intention: Focusing on the mediating effects of recognition of music and movement activities. Korean Journal of Child Studies, 37(2), 1-11. doi:10.5723/ kjcs.2016.37.2.1

Lee, J.-S. (2003). Interaction between a teacher and children depending on teaching experience and children's age (Master's thesis). Retrieved from http://www.riss.kr/link?id= T9433386

Lee, S.-K., \& Kim, H.-W. (2016). The structural relationships among classroom environment, teacher-child interaction, children's cognitive ability and peer interaction. Journal of Learner-Centered Curriculum and Instruction, 16(10), 925945. doi:10.22251/jlcci.2016.16.10.925

Lim, B.-Y., Oh, J.-H., \& Choi, N.-J. (2008). The impact of humor based activities on young children of differing levels of emotional intelligence in terms of self-concept, humor appreciation and sense of humor. Korean Journal of Early Childhood Education, 28(1), 185-209. doi:10.18023/ kjece.2008.28.1.009

Lim, H., \& Bang, E. (2017). Influence of playfulness, emotional intelligence and music education awareness on teaching initiative for music in childcare teachers. Korean Journal of Early Childhood Education, 37(2), 103-125. doi:10.18023/ kjece.2017.37.2.005

Moon, T. (2005). Relationships between kindergarten teachers' achievement orientation and teacher efficacy. Korean Journal of Child Studies, 26(4), 21-33.

Oh, H. J. (2008). A study on mother's playfulness comparison between general children and child patients under play therapy 
(Master's thesis). Retrieved from http://www.riss.kr/ link?id=T11220294

Park, H. S., \& Kim, K. W. (2004). A study on the mother's playfulness, parenting efficacy, and parenting stress. Korean Journal of Play Therapy, 7(1-2), 13-24.

Seo, J.-E., \& Lee, S.-M. (2014). Influence of infant teachers' play beliefs upon teacher-infant interaction-Focusing on the mediating effect of play-teaching efficacy. The Journal of Korea Open Association for Early Childhood Education, 19(6), 129-150.

Shim, S., Cho, S., Lee, J., Lee, C., Lee, S., \& Lee, H. (2014). Introduction to early childhood education (4th ed.). Seoul: Changjisa.

Shin, E. (2000). The effects of teacher's efficacy beliefs about play on teacher-child interaction and children's play. Journal of Early Childhood Education, 20(1), 27-42.

Shin, E., \& Park, H. (2006). Effects of teacher education about pretend play on teachers' efficacy of play, teachers' intervention, and levels of children's social pretend play. Korean Journal of Early Childhood Education, 26(6), $287-$ 310.

Shin, E., Yu, Y.-E., \& Park, H.-K. (2004). Developing and validating an instrument to assess the relationship between kindergarten teachers' efficacy beliefs on play and their beliefs on play management practice. The Journal of Early Childhood Education, 24(1), 49-69.

Shin, H. J., \& Shin, N. (2014). Effects of preschoolers' temperament and relationships with teachers on their peer interaction. Journal of Korean Child Care and Education, 10(3), 47-68. doi:10.14698/jkcce.2014.10.3.047

Wee, S., \& Park, E. (2007). Exploration of related variables to teacher strategy and child strategy of teacher-child interaction about play rules in kindergarten. Korean Journal of Human Ecology, 16(6), 1169-1183.

Yi, J. J., \& Choi, N. Y. (2013). The relationship among teacher's play beliefs, play teaching efficacy and teacher-children interaction. Korean Journal of Child Education and Care, 13(3), 183-203.

You, M., \& Yoo, M. S. (2008). The effects of maternal beliefs about play and emotional expressiveness on children's playfulness. Korean Journal of Play Therapy, 11(4), 53-63.

Yu, Y. E., \& Shin, E. S. (2005). Differences in children's constructive play quality by teacher's play teaching efficacy. Korean Journal of Child Studies, 26(6), 111-126.

\section{ORCID}

Su Mi Lim

Hae Shin Hwang
http://orcid.org/0000-0001-7078-235X

http://orcid.org/0000-0002-2905-354X
Received April 29, 2019

Revision received June 24, 2019

Accepted July 18, 2019 